\title{
The NOTHING ELSE Brand: A Case Study
}

\author{
Dave Brown', Bruce Donaldson², Andrew Parsons³, Deborah Macrae'2, \\ John Kelleher ${ }^{4}$, Mary Yan², Elaine Rush ${ }^{2 *}$ \\ ${ }^{1}$ School of Communications (Advertising Creativity), Auckland University of Technology, Auckland, New Zealand \\ ${ }^{2}$ School of Sport and Recreation (Nutrition), Auckland University of Technology, Auckland, New Zealand \\ ${ }^{3}$ Department of Retailing, Auckland University of Technology, Auckland, New Zealand \\ ${ }^{4}$ Culinary Arts Department, School of Hospitality and Tourism, Auckland University of Technology, Auckland, \\ New Zealand \\ Email: ${ }^{*}$ elaine.rush@aut.ac.nz
}

Received 18 February 2015; accepted 7 March 2015; published 11 March 2015

Copyright (C) 2015 by authors and Scientific Research Publishing Inc.

This work is licensed under the Creative Commons Attribution International License (CC BY). http://creativecommons.org/licenses/by/4.0/

(c) (i) Open Access

\section{Abstract}

The NOTHING ELSE food label, created at the Auckland University of Technology, lists the eight or less easily recognized ingredients on the front-of-pack within a circular band. This report describes the evolution of the label into a stand-alone brand for products including nuts, dried fruit, biscuits and water sold in four cafes at the university. In partnership with an established food manufacturer a NOTHING ELSE healthier snackbar was developed and sold through the university fitness centres with sales being tracked electronically by time, day and quantity. Consumers/purchasers of this NOTHING ELSE bar were asked why they bought the bar and when they would eat it as well as if they would buy the bar again and why/why not. Two thirds of the 43 respondents said that they would buy the bar again. Three key reasons for repurchase were identified: taste ( $\mathrm{n}=$ $12)$, "healthy" $(n=11)$ and "natural ingredients" $(n=10)$. Positive comments about the ingredients included: no additives or preservative, the low/no added sugar, and the presence of fibre demonstrating that this unique brand concept was meeting a consumer need for transparent product information. The next steps are commercial production of the snackbar and market expansion within the university.

\section{Keywords}

Consumer-Driven Product Development, Food Labelling, Nutrition, Ingredients, Brand Transparency

\footnotetext{
*Corresponding author.
} 


\section{Introduction}

Over the past decade trends in food consumption have shifted due to demands from consumers for more authenticity and transparency [1]-[3]. There is now close scrutiny of ingredients by consumers, which is affecting the way food is packaged and labelled. This is a result of growing interest in food and beverages made from natural and familiar ingredients, as an alternative to products made with ingredients that are synthetic and unfamiliar [4]. There is also increasing concern over front of pack claims overpowering the ingredients lists and nutritional facts presented on the back of pack [5].

Currently the diversity of food products on supermarket shelves are in direct competition with each other; one might be made with natural less refined ingredients while another may be made with many ingredients including colours and preservatives and more refined ingredients including sugar and white flour. However, the listing of those ingredients is only required to be on the back of pack [6], so does not directly affect the first impression of the product by browsing shopper.

The authors contend that there is a need for clear information about food ingredients to be provided to the consumer as well as the development of healthier and commercially viable products. This case study overviews the development of the NOTHING ELSE concept from a label to a brand, then the development of a healthier snackbar that underwent a pilot study of sales and consumer responses to the bar within a university.

It is important to understand consumer "choice” when consumers are purchasing new food products. Choice is related to sensory science, but also consumer behaviour. Both sensory science, to investigate aspects of consumption of the product, and research, that investigates actual purchase of the product, are required to confirm the likely commercial viability of new products before they are launched [7].

The aim of this study was to show both proof-of-principle and proof-of-practice of consumer purchasing behavior through the development of an informative front of pack label and brand and production of a prototype and novel packaged food product that could be demonstrated to be healthier than other products, but also one that the consumer would buy on more than one occasion.

\section{Method}

\subsection{Development of NOTHING ELSE Label and Brand}

The development of the NOTHING ELSE label started with research in semiotics using a methodology based on multimodal discourse analysis. The methodology covers visual and textual modes of communication used in packaging design [8]-[11]. Packaging and food labelling [12]-[14] is a combination of both visual cues (picture of product and graphic elements) and textual cues (name, ingredients and nutritional value), within a regulatory framework. This research was informed by a discourse analysis [15] looking at purchasing actions within a supermarket [16] [17], the history of consumption trends from the mid-twentieth century social practice-the consumerization of culture [18] and the twenty-first century social practice of sustainable consumption [19]-[21].

As a result of this work a label, in the shape of a circular band, was created and called NOTHING ELSE. Inside the band is the list of ingredients. The label is designed to be printed on the front of the pack so that customers see the ingredients upfront in a clear, legible font.

The NOTHING ELSE label concept was presented to an international biscuit manufacturer for feedback. The brand manager was positive about its potential and suggested the idea be pitched to local New Zealand manufacturers who had similar products using only "natural”/“real” ingredients. Although the four manufacturers consulted expressed interest in the label concept, they considered that the application was not commercially viable as a levy-based licensing model. On the advice of the biscuit manufacturer a brand steering committee at Auckland University of Technology (AUT) was formed. One of the members (Elaine Rush) who was the nutritional advisor, suggested the idea be presented to Brand Support, a company specialising in marketing cause-related products.

The directors of Brand Support were enthusiastic. They suggested developing NOTHING ELSE as a brand instead of developing a label, and support funding was made available by Brand Support to develop and launch NOTHING ELSE within AUT.

The development from label to brand required a much greater contribution from the AUT community. This case study grew by making the project more collaborative, involving input from students in the fields of nutrition, public relations, graphic design, product design, advertising creativity and marketing. 
The NOTHING ELSE logo was further developed as a "circle of trust"- - a flexible design mark that could adapt to a range of food and beverage products. On all products the front of the pack would feature the brand name circling the ingredients, and the back would display mandatory items such as nutritional information and barcode. NOTHING ELSE is a registered trademark (New Zealand Intellectual Property Office 843901).

Five snack items using nuts and dried fruit were developed, as well as an artesian water. The brand was launched in four cafes on two AUT University campuses using ambient messages that promoted the brand values. NOTHING ELSE snacks were displayed on counter top racks made by product design students, while the water was displayed in chillers. Staff and students were offered free samples and flyers at various locations, including lecture theatres. These products have now been sold in the university cafes for more than five years. The university has more than 27,000 students and 2000 staff members.

To strengthen the NOTHING ELSE brand communication a manifesto was created using the brand tagline “THE UPFRONT BRAND”. The manifesto was printed as a small flyer (Figure 1) that would be used to state the essence of the brand values. The flyer was used as a handout in conference promotion bags as well as a way to introduce the brand to new customers.

\subsection{Developing the Snackbar}

Following on from the successful launch of the NOTHING ELSE brand in the AUT university campus cafes the next challenge was to develop a commercially viable muesli style bar with a nutrition profile score that would allow general health claims to be made (Australia New Zealand Food Standards Code, 2014). The NOTHING ELSE label would emphasize the list of ingredients on the front as a marketing distinction to the target audience. Ideally the bar would meet a number of health parameters such as a low glycemic index, a high fibre and a low sodium content and also be dairy-free.

Ingredients and facilities to develop the first stage samples of the bar were provided by a commercial partner. After considerable trials with recipes, using different ingredients, the eight ingredients for the final recipe were: oats/oat bran, dates, almonds, manuka honey, egg white, cinnamon, sunflower oil and sea salt. The first 100 samples were hand-made and baked in a domestic oven.

A small sensory trial for liking was undertaken with a group of men and women aged 60+ years who were members of a group of fitness enthusiasts called "Never2Old". The Never2Old active aging programme was introduced at the Akoranga campus at AUT University as an exercise programme for semi-retired and retired people. Those who tasted the bar responded favourably to the samples, although some found the taste was dom-

\section{NOTHING ELSE THE UPFRONT BRAND}

NOTHING ELSE is the first food brand to list all the ingredients on the front of the pack. The ingredients are natural and familiar - no preservatives, no additives, nothing artificial.

\section{BRAND GUIDELINES}

- NOTHING ELSE products list ingredients upfront

- NOTHING ELSE products are made with food everyone can understand

- NOTHING ELSE food products are independently reviewed

- NOTHING ELSE makes purchasing decisions easier to read and understand

- NOTHING ELSE puts consumer needs first

\section{OUR STORY}

NOTHING ELSE was created at AUT university from research for an MPhil on sustainable consumption by Dave Brown. Dave's research found shoppers are moving towards authentic and transparent food labeling and he wanted to find a simple solution for consumers who were confused by too much product information. NOTHING ELSE started with small snacks and bottled artesian water followed by ANZAC biscuits launched across AUT cafes. The brand is looking to grow its range and expand into wider food markets.

Want to hear more about NOTHING ELSE?

Contact Dave Brown | (09) 921-9999 ext 7031 | dave.brown@aut.ac.nz

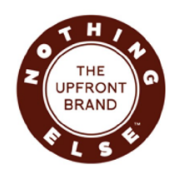

Like us on Facebook Google - nothing else food

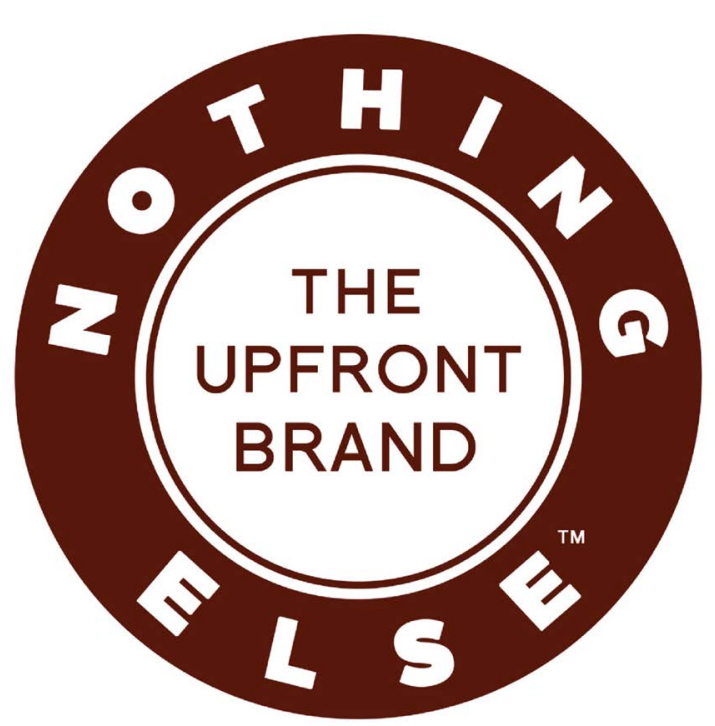

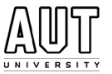


inated by the dry texture of the product and needed to drink water before finishing. After another six months of fine tuning a larger survey with two target age groups was undertaken. The first group was with AUT University students and the second group with the Never2Old group.

The survey compared taste, satiety, texture, as well as perceived naturalness and healthiness with three other high selling muesli bars made by well established brands, and included a blind test as well as one where the brand label was shown next to the product sample (paper in preparation).

Following this the recipe was further refined by adjusting the proportions of ingredients and a larger production run (1000 bars) undertaken. Two of the AUT University Sport and Fitness Centres agreed to sell the bar commercially and to provide electronic transaction records of the number sold, place, time and date.

An anonymous questionnaire was constructed that asked for sex and age group of the respondent, whether they had eaten the bar before, how they found out about the bar and why they were buying the bar. They were also asked when they would eat the bar and whether they would buy the bar again, and if so why or why not. This questionnaire was placed at the reception desk at the bars point of sale; the AUT University Sport and Fitness Centres. A box was provided to place completed questionnaires. The questionnaire, and the way it was administered, was approved by the Auckland University of Technology Ethics Committee.

There was limited in-house promotion of the bar; one email to all campus staff, one announcement via the staff intranet (Global Network), posters (displayed at the fitness centres) and an announcement on the facebook pages for the NOTHING ELSE brand and the Never2Old group. An invitation to a single information session, at the North Shore campus, about the bar and nutrition in general was advertised to the Never2Old group.

\section{Results}

The initial launch of the first NOTHING ELSE branded products was an immediate success with brisk sales of both snacks and water. However, over time, the snack sales slowed. To improve sales the snacks were pared back in scale and range from a 120 gm pack to a 30 gm pack, which sold for a simple \$2 exchange in line with the water. The range was reduced to the two most popular items: cashew nuts and cranberries with almonds. The new format improved sales which have continued at a steady rate to the present (five years). From the day of launch sales figures for the water have been robust. Students have responded favourably to the brand ethos of being "upfront" by sending over 400 "likes" on the NOTHING ELSE Facebook page.

The launch of the nut snacks was followed by an ANZAC biscuit using the original recipe of natural ingredients, which retailed for $\$ 2$ for a pack of two biscuits. This biscuit, a traditional recipe for Australia and New Zealand since World War I, had a six-month shelf life and was very popular. However, further opportunities for distribution were required to make it economically viable and its production was discontinued.

Following the development of the final form and front of pack label for the snackbar (Figure 2), the bar was prepared and packaged by the commercial partner. The sales plan for the new bar was to have each Never2Old

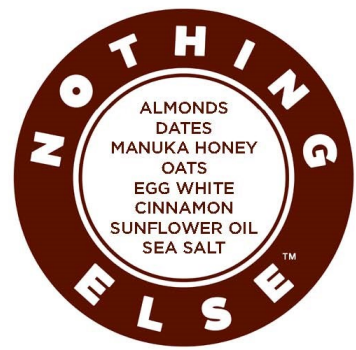

LIFESAVER

SNACKBAR

Figure 2. Front of pack label of the NOTHING ELSE snackbar. 
member try a free sample and then measure sales over the following three weeks. The bar was priced competitively at \$2 for $50 \mathrm{~g}$ and customers were invited to complete a point of sale questionnaire about their perceptions of the bar and its branding. Marketing was minimal with only one campus wide email advising that the bar was on sale and two announcements in the global weekly newsletter emailed to all staff.

Over a period of three weeks 43 consumers returned the one page questionnaire $(n=34)$ or emailed $(n=9)$ comments. Most of the respondents were female (70\%), the remainder were male (19\%) or sex was not stated (11\%). Of the 35 respondents who provided their age 15\% were aged less than 40 years, $44 \%$ were aged 41 to 60 years, and $41 \%$ were aged 61 years or more. In this period a total of 334 bars were sold, of which $19 \%$ of these sales were for more than one bar and $7 \%$ for 5 or more bars.

Of the 43 respondents $67 \%$ (29) indicated they had not tried the NOTHING ELSE bar before (five had and nine did not answer). Respondents found out about the NOTHING ELSE snackbar from the $\mathrm{N}_{2} \mathrm{O}$ information session (27\%), word of mouth (19\%), email (15\%) and from an on campus health expo where the bar could be sampled (42\%). No one mentioned having seen the posters.

Two thirds of all respondents said that they would buy the bar. Three key reasons for purchase and repurchase were identified: taste $(n=12)$, "healthy" $(n=11)$ and "naturalness" of ingredients $(n=10)$. Only five respondents mentioned value as a reason. Positive comments about the ingredients included that there were no additives, no preservative, low and/or no added sugar, and the presence of fibre.

Of the five respondents that commented that they would not buy the NOTHING ELSE snackbar again the two key reasons identified were that it was dry/too dry $(n=3)$ and/or bland $(n=2)$. Other related reasons included texture-powdery and "cardboardy".

Of the 31 respondents who answered when they would eat the bar, 26\% said they would eat it straight away, however most respondents indicated that the bar would be eaten between meals or as a snack (49\%) or when hungry (39\%). Respondents could provide more than one answer to this question.

Respondents that would (re)purchase the NOTHING ELSE snackbar suggested that potential improvements could be made, the main reason was in relation to dryness and texture with words such as "not so dry and crumbly” $(\mathrm{n}=7)$ used to describe why. Other suggestions for improvement included making it gluten-free, having a lower carbohydrate/higher fat option, increasing the font size on the packaging, using recycled/biodegradable packaging and making the NOTHING ELSE bar shorter but thicker to help maintain its integrity.

The fitness centres are open between 6.00 am and 9.00 pm during weekdays. The Never2Old group attend the centre between 9.30 am and 10.30 am Monday to Friday, and also between $13.30 \mathrm{~h}$ and $14.30 \mathrm{~h}$ Monday, Tuesday and Thursday. Almost one third of sales occurred in this time. The greatest number of sales occurred between $1101 \mathrm{~h}$ and $1300 \mathrm{~h}$ (37.3\% of all sales) which is not a time when the Never2Old group attend. The most sales were therefore to other staff, students or gym members of the university.

\section{Discussion}

In the context of food, the long-term health benefits of consuming food made with natural ingredients and containing whole, rather than refined and processed ingredients, is a step toward more sustainable living. This is in line with the evidence that a growing proportion of customers are choosing products that are seen as "part of the solution" not "part of the problem" [18].

NOTHING ELSE-THE UPFRONT BRAND is intended to allow customers to have easy access to ingredient information so that they can make an informed choice. The brand does not intend to preach an overt message of superiority. It simply lists the ingredients upfront so the customer is free to take it or leave it.

We have shown in this report that the reasons consumers bought the bar are related, in part, to perceived healthiness and naturalness. Purchasing decisions are subject to behaviours and mental decision making processes influenced by a variety of factors including demographics, socioeconomic, knowledge/information, past experiences/exposures and marketing/advertising [22]. There appears, however, to be few studies that have investigated concurrently sales, the reasons consumers make food purchasing decisions and consumers purchase intent, i.e. their plan to purchase a particular item in the future. Purchase intent of food products, for example, has been measured by others [23] [24] but not alongside, or supported by, actual sales data.

In this small, but comprehensive, survey new insights have been provided into purchasing behaviour of those respondents who filled in the questionnaire. While data anonymity does not allow for matching of intention with actual purchasing of those who completed the questionnaire, the fact that two thirds indicated they would buy the bar again based on their actual initial purchase is a positive indication of purchase intent. This is similar, in 
principle, to other studies that have found purchase intent (non-food based) to be a good predictor of product choice [25] [26]. However, there is still a degree of uncertainty in respect to how purchase intent applies to food products, particularly in situations where choice involves a low level of involvement as well as little time or money [27] [28]. While we did not expect that everyone would like the bar, or consider buying it again, the purchase of more than one bar at a time (19\% of all sales) and the repeat purchases (personal observation) are encouraging.

In the setting of the AUT University Sport and Fitness centre the NOTHING ELSE snackbar appears more likely to be purchased by older health conscious consumers who have gym memberships and are generally active, although this may spread to a younger group as well. Anecdotally the receptionists noted that the people purchasing the bar were of a wide age range and not necessarily only gym members. They commented that staff and students that they had not seen before came to the gym to purchase the bar with a number returning to buy more bars.

A major limitation of this case study is the small number of participants who completed the questionnaires. As a proof of principle this ongoing project has a number of strengths. The AUT University has a total population of 30,000 staff and students, and therefore provides, in term time, a ready market to launch a start-up brand. The project also allows students to be involved collaboratively in the brand promotion, which enables the brand values through education and participation to be reinforced by the younger generation of consumers. A percentage of all profits from sales is retained in a research fund for further brand development and student support.

Establishing a market depends on both attracting new and maintaining existing customers. Brand trust, together with loyalty, are often identified as key features of a successful product. This was a unique aspect of this product, a product and brand that was not only developed by AUT University staff, but one designed for the greater health and wellbeing of AUT staff (by AUT for AUT). Likewise the NOTHING ELSE snackbars were promoted and sold through the fitness centres at AUT, and this kind of support and cooperative action may be hard to replicate in the wider commercial world. Furthermore, unlike most commercial products, NOTHING ELSE bar consumers had direct access to those involved in developing and producing the bar, and this transparent and "personalized" approach has been a strength of the project enabling and encouraging honest and constructive feedback. The unsolicited emails received were not only an indication of the interest in the bar and the research, but the also the support for an AUT initiative. The production of a product by a university has in itself a certain trustworthiness as clearly it is not being sold for personal profit.

The next steps are to work with our commercial collaborator with a view to a trial contract production of larger numbers of the snackbar for sale through the AUT University sport and fitness centres, cafes and at University functions before gaining wider distribution. This unique NOTHING ELSE brand concept has demonstrated how a need for consumer driven-research may help meet the growing consumer demand for more transparent product information on food packages.

\section{Acknowledgements}

The authors thank John Kelly, Timothy Bowater from Culinary Arts, AUT University for their technical assistance and support. The development of the NOTHING ELSE snackbar was led by Professor Elaine Rush, Professor of Nutrition at AUT. Research funding for the project was sourced from AB Foods Ltd., a company specialising in contract baking whose owner is Peter Tan, and Callaghan Innovation in partnership with AUTEL which is the commercialisation arm of AUT. AB Foods also provided the use of a kitchen on the site of the manufacturing base in Mangere, Auckland. Sensory analysis expertise was provided by Dr. Nazimah Hamid. Marketing and branding of the snackbar was developed by Dave Brown, lecturer in Advertising Creativity at the School of Communication Studies at AUT, and Mitali Purohit, project developer at AUTEL. The authors are all members of the AUT food network, a cross disciplinary and faculty group of researchers.

\section{References}

[1] Boyle, D. (2004) Authenticity: Brands, Fakes, Spin and the Lust for Real Life. Harper Collins UK, London.

[2] Ewen, S. (2001) Captains of Consciousness. Basic Books, New York.

[3] Grant, J. (2009) The Green Marketing Manifesto. John Wiley \& Sons, London.

[4] Pollan, M. (2008) In Defence of Food: The Myth of Nutrition and the Pleasures of Eating. Penguin UK, London.

[5] Nestle, M. and Ludwig, D.S. (2010) Front-of-Package Food Labels: Public Health or Propaganda? Journal of the Ameri- 
can Medical Association, 303, 771-772. http://dx.doi.org/10.1001/jama.2010.179

[6] Australia New Zealand Food Safety Authority (2014) Australia New Zealand Food Standards Code—Standard 1.2.7 -Nutrition, Health and Related Claims. http://www.comlaw.gov.au/Series/F2013L00054/Compilations

[7] Grunert, K.G. (2003) Can We Understand Consumers by Asking Them. Marketing Research, 15, 46.

[8] Iedema, R. (2003) Multimodality, Resemiotization: Extending the Analysis of Discourse as Multi-Semiotic Practice. Visual Communication, 2, 29-57. http://dx.doi.org/10.1177/1470357203002001751

[9] Joy, A., Sherry Jr., J., Venkatesh, A. and Deschenes, J. (2009) Perceiving Images and Telling Tales: A Visual and Verbal Analysis of the Meaning of the Internet. Journal of Consumer Psychology, 19, 556-566. http://dx.doi.org/10.1016/j.jcps.2009.05.013

[10] Kress, G. and Van Leeuwen, T. (2006) Reading Images: The Grammar of Visual Images. Routledge, Oxon.

[11] Norris, S. and Jones, R.H. (2005) Discourse in Action. Routlege, London.

[12] Baltas, G. (2001) Nutrition Labelling: Issues and Policies. European Journal of Marketing, 35, 708-721. http://dx.doi.org/10.1108/03090560110388178

[13] Messaris, P. (1997) Visual Persuasion: The Role of Images in Advertising. Sage, London.

[14] Parsons, A.G. and Schumacher, C. (2012) Advertising Regulation and Market Drivers. European Journal of Marketing, 46, 1539-1558. http://dx.doi.org/10.1108/03090561211259970

[15] Brown, D. (2010) Changing Modal Values through Sustainable Consumption of Food. Master of Philosophy (Communication Studies), AUT University. http://aut.researchgateway.ac.nz/handle/10292/1001

[16] Arvidsson, A. (2006) Brand Management. In: Brewer, J. and Trentmann, F., Eds., Consuming Cultures, Global Perspectives: Historical Trajectories, Transnational Exchanges, Berg Publishers, New York, 71-94.

[17] Jones, R.H. (2005) Sites of Engagement as Sites of Attention: Time, Space and Culture in Electronic Discourse. In: Jones, R.H. and Norris, S., Eds., Discourse in Action, Routledge, London, 141-154.

[18] Trentmann, F. (2006) Genealogy of the Consumer. Berg Publishers, New York.

[19] Hamilton, C. (2003) Growth Fetish. Allen \& Unwin Australia Pty Ltd., Crows Nest. Japanese Version Translated by Shimada, Y. (2004) Keizai Seicho no Shinwa karano Dakkyaku.

[20] James, O. (2008) The Selfish Capitalist. Vermilion, London.

[21] Kasser, T. (2002) The High Price of Materialism. MIT Press, Boston.

[22] Grunert, K. (2003) Purchase and Consumption: The Interdisciplinary Nature of Analysing Food Choice. Food Quality and Preference, 14, 39-40. http://dx.doi.org/10.1016/S0950-3293(02)00033-2

[23] Guinard, J-X., Smiciklas-Wright, H., Marty, C., Sabha, R.A., Soucy, I., Taylor-Davis, S. and Wright, C. (1996) Acceptability of Fat-Modified Foods in a Population of Older Adults: Contrast between Sensory Preference and Purchase Intent. Food Quality and Preference, 7, 21-28. http://dx.doi.org/10.1016/0950-3293(95)00019-4

[24] Haddad, Y., Haddad, J., Olabi, A., Shuayto, N., Haddad, T. and Toufeili, I. (2007) Mapping Determinants of Purchase Intent of Concentrated Yogurt (Labneh) by Conjoint Analysis. Food Quality and Preference, 18, 795-802. http://dx.doi.org/10.1016/j.foodqual.2007.01.009

[25] Bemmaor, A.C. (1995) Predicting Behavior from Intention-to-Buy Measures: The Parametric Case. Journal of Marketing Research, 32, 176-191. http://dx.doi.org/10.2307/3152046

[26] Cobb-Walgren, C.J., Ruble, C.A. and Donthu, N. (1995) Brand Equity, Brand Preference, and Purchase Intent. Journal of Advertising, 24, 25-40. http://dx.doi.org/10.1080/00913367.1995.10673481

[27] Al-Weqaiyan, A. (2005) A Cross-National Study of Repurchase Intentions of Fast-Food Meals. Journal of International Food \& Agribusiness Marketing, 17, 95-116. http://dx.doi.org/10.1300/J047v17n01_06

[28] Beharrell, B. and Denison, T.J. (1995) Involvement in a Routine Food Shopping Context. British Food Journal, 97, 2429. http://dx.doi.org/10.1108/00070709510085648 